\title{
Chapter 3 \\ The Design and Validation \\ of the Renewed Systems-Oriented Talent \\ Management Model
}

\author{
Arnold J. Brouwer, Bernard P. Veldkamp and Marieke Vroom
}

\begin{abstract}
Within the field of talent management, it is common to make use of assessments in order to select and appoint the best fitting human talent at the right moment and for the right time. Characteristic for current assessment instruments is that they primarily focus on measuring the talents and motives of (potential) employees. There is no known psychometric test instrument available that links these human characteristics to the strategy and purpose of an organisation. In order to bridge this gap, this chapter introduces the systems-oriented talent management (STM) model. The STM model is elaborated into three STM diagrams in which business purpose and human talent are aligned from both a managerial and a psychological perspective. The management building blocks framework and the systems theory, applied to the field of organisation, are used to describe the interrelations between the components of the STM model. Lexical-semantic analyses are conducted to link human talent to the core elements of an organisation's purpose. This study contributes to achieving a sustainable match between organisations and their employees that, in our rapidly changing world, is able to move along with continuous adaptations in business strategy and the associated adjustments in team compositions and tasks. However, not only the workplace is subject to change. The field of education is affected as well, and the pupils and students of today are the employees of tomorrow. Therefore, this chapter also explores the possible application of the STM in the educational world.
\end{abstract}

\footnotetext{
A. J. Brouwer $(\bowtie) \cdot$ M. Vroom

RCEC, Vaassen, The Netherlands

e-mail: a.j.brouwer@rcec.nl

B. P. Veldkamp

University of Twente, Enschede, The Netherlands

(C) The Author(s) 2019

B. P. Veldkamp and C. Sluijter (eds.), Theoretical and Practical Advances

in Computer-based Educational Measurement, Methodology of Educational

Measurement and Assessment, https://doi.org/10.1007/978-3-030-18480-3_3
}

47 


\subsection{Introduction}

\subsubsection{Problem Situation and Purpose of the Study}

Our ever more rapidly changing world demands a lot from organisations, and in particular their HRM specialists, to find, retain and promote the right people for the right positions. In their search for support, a growing number of organisations turn to talent management, a specialisation defined as the process of discovering, developing and retaining top talent (Michaels et al. 2001). Talent management focuses on the recruitment and selection of the right people, helps employees develop in their professional roles and guides them to the next step in their careers. The aim is to be able to continuously anticipate the internal and external changes that all organisations face (Berger and Berger 2011).

Within the field of talent management, it is common to select employees by conducting assessments. Measuring talents and predicting success rates of candidates for certain positions within companies is a valuable way to select potentials and to prevent mismatches (Berger and Berger 2011; Schoonman 2013). This procedure is founded in psychological testing techniques, defined as systematic and standardised procedures for measuring human characteristics of a candidate (Smith and Robertson 1986; Michaels et al. 2001).

Although the field is equipped with many reliable and valid test instruments, it is surprising that the majority of these measures solely map the human characteristics side of the match between the organisation and its worker. This is done by either identifying inner characteristics ('attributes and/or attitudes') or diagnosing visible behaviour and skills ('abilities'; McDonnell and Collings 2011). Together with intelligence tests that measure cognitive capabilities, these attributes, attitudes and abilities are presumably the strongest predictors for success or failure (Schmidt and Hunter 1998; Schmidt et al. 2016).

Next to these instruments that measure people's inner and/or visible characteristics, the field of management science designed different models to represent an organisation as a mixture of jointly interacting management building blocks (Galbraith 2002; Hendricks and Singhal 1996; Tillema and Markerink 2006; Nieuwenhuis 2006). Even though this resulted in clear managerial constructs that, from their nature, could potentially be measured as well, there is no known psychometric test instrument available that links the talents and motives of (potential) employees to the strategy and purpose of an organisation.

Because such an instrument is missing, HR consultants and other assessors have to depend on their own knowledge and expertise in psychology and business administration to make this connection (Cable and Yu 2007; Van Beirendonck 2010). In practice, this is a difficult task, which often results in a limited match between those characteristics and the organisation. Vice versa, HR consultants also face difficulties in indicating exactly what the organisation is looking for in terms of human qualities. Not rarely this leads to broad, and sometimes contradictory, organisational strategy and culture models and individual function and competence profiles. Who has not 
read mission statements or descriptions of core values in which both staff and clients hardly recognise themselves or the firm? And who has not seen the advertisements in which the candidate sought after is a result-oriented go-getter who is independent, but also works well in teams, and is not only flexible but also meticulous?

Consequently, the long-term results of strategy and culture change programmes and recruitment and selection procedures often are unsatisfactory. While at shortterm, there seems to be a match between the employee and the organisation, problems arise when the job content is adjusted or the organisation changes. As a solution, companies often opt for top-down management interventions, short employment contracts, or onboarding: a period in which employees learn the knowledge, skills and behaviours to be effective in the renewed organisational context or in their new function, to first check whether it really works. As a result, the organisation is confronted with high costs and both parties might end up disappointed.

To integrate psychological questionnaires that test human characteristics with models for representing organisations in a series of managerial blocks, Brouwer (2012) introduced the systems-oriented talent management (STM) model. This model is elaborated into three initial STM-scan diagrams in which business purpose and human talent are aligned from both a managerial and a psychological perspective.

The three initial STM diagrams were implemented as an online testing instrument, named STM-scan. This initial version of the STM-scan has been used over 1000 times as talent management instrument within different Dutch companies. Multiple intermediate evaluations established that this initial version of the STM-scan was experienced as a helpful assessment instrument for answering talent management questions regarding adoption and/or adjustment of corporate strategy and culture, recruiting and selecting new personnel, coaching and developing employees, and, outplacement and career advice to employees. For example, in Brouwer (2018, Chap. 6) interviews were held with a panel of four talent management experts who have several years of experience with the STM: a recruiter, a HRD consultant, a career coach and a business coach. The recruiter explains that the foremost value of STM lies in getting a sharp image of someone's qualities in a short amount of time. "And when you have a clear picture of what is needed [within the organisation], you can quickly come to the conclusion whether or not there is a fit." According to the career coach this accelerates the intervention process: "I dare say that it saves me at least a few appointments in a coach assignment." All four experts assent that the STM can provide insight into individuals, teams and organisations, and gives a clear image of their strengths and weaknesses. It makes it possible to look at people "for who they are, and not for what they show," says the business coach. This helps both the test taker and the test professional to more quickly find detailed answers to talent management questions. "That is often what is most important for clients who make use of the STM: they want to achieve their goals as effectively as possible. [...] Ultimately, organisations hire people to realise something, not just because they like to employ people," notes the HRD consultant (pp. 174-175).

Since the initial STM was best practice oriented rather than evidence-based, a series of qualitative and quantitative studies was done to (re)design and validate this first model (Brouwer 2018). This resulted in a renewed evidence-based STM model 
and its elaboration in three renewed STM diagrams, that could take the place of the initial three STM-scan diagrams. The renewed STM not only provides a theoretical framework to align human talent and organisational purpose, but also supports HR consultants and other professionals with tools that measure both human talent and organisational purpose, and quantify their connection.

The management building blocks framework (MBBF; Nieuwenhuis 2006) and systems theory (Katz and Kahn 1966; Meadows 2008) are used to elaborate the interrelations within the new STM model. This provides a renewed way of linking human talent to the core elements of an organisation's purpose (Barile 2006, 2008; Mele et al. 2010), and is assumed to result in a fit between corporate and personal identity instead of a fit between a person's visible skills and a specific job profile that in this rapidly changing world is subject to continuous alteration.

\subsection{Theoretical Framework}

\subsubsection{The Management Building Blocks Framework}

Within the field of management science there are different models for representing an organisation as a dynamic and a constantly adapting organism. Widely recognised models are the 7S model (Peters and Waterman 1998), the Star Model (Galbraith 2002) and the European Foundation for Quality Management (EFQM) excellence model (Hendricks and Singhal 1996) with its application for the Dutch market in the INK (Instituut Nederlandse Kwaliteit) management model (Tillema and Markerink 2006). As visualised in Fig. 3.1, a common feature in these models is the use of a set of five management building blocks that jointly interact as a value chain, describing the composition of and joint interactions within the primary business process. This value chain is defined as the management building blocks framework, or MBBF (Nieuwenhuis 2006).

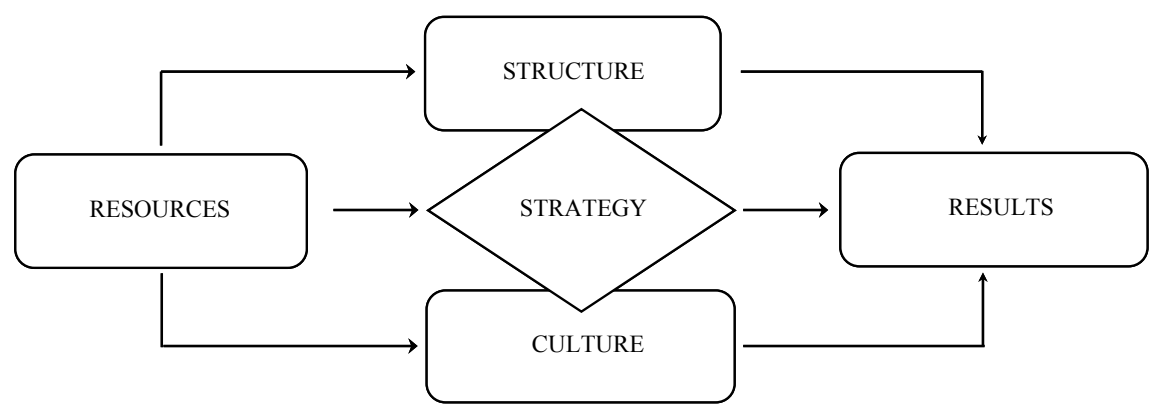

Fig. 3.1 The management building blocks framework, or MBBF (Nieuwenhuis 2006) 
From a managerial point of view, the first building block of the MBBF, structure, is seen as organisational structure. This describes the way activities such as task allocation, coordination and supervision are directed towards the achievement of organisational aims (Pugh 1990). Structure affects organisational actions towards reaching the organisation's purpose in two ways: (1) it provides the foundation on which operating procedures and routines rest, and, (2) it determines which individuals get to participate in which decision-making processes, and to what extent their actions shape the organisation's purpose (Jacobides 2007).

The second building block, culture, is seen as organisational culture and defined as a set of shared mental assumptions that guide interpretation and action in organisations by prescribing appropriate behaviour for various situations (Ravasi and Schultz 2006). This set of shared assumptions is tangible in the organisation's climate, which is the shared meaning organisational members attach to the events, policies, practices and procedures they experience and the behaviours they see being rewarded, supported and expected (Ehrhart et al. 2014). Whereas organisational culture represents the predefined and desired image, the organisational climate embodies the actual identity.

The third building block, strategy, defined as business strategy, is known as the formulation and implementation of the organisation's purpose and initiatives taken by employees on behalf of its stakeholders (Nag et al. 2007). According to Wit and Meyer (2011), business strategy consists of two dimensions: (1) the strategy process, expressed in the amount of effectiveness of the organisation design, and (2) the strategy content, measured from the outcome of its employees' contribution.

For the execution of the organisation's purpose, an organisation needs the best fitting human talent, represented in the fourth building block, resources. The effect of the execution of the organisation's purpose is visualised in the interaction between strategy, consisting of structure and culture, and the building block resources. Its outcome is expressed in the fifth building block of the MBBF, results.

To elucidate the relationship between the organisation's purpose and human talent in order to find ways to gain the desired results, a systems-oriented view on the composition of and joint interactions between these five management building blocks is needed. This is found in the systems theory.

\subsubsection{Systems Theory}

Systems theory is an interdisciplinary theory about every system in nature, society and many scientific domains, as well as a framework with which phenomena can be investigated from a holistic approach (Capra 1997). It encompasses a wide field of research with different conceptualisations and areas of focus. Katz and Kahn (1966) applied systems theory to the field of organisations. Studied from its managerial context, systems theory is a theoretical perspective that helps to analyse the organisation seen as a whole and not as simply the sum of its elementary parts (Meadows 2008). Every organisation is seen as a group of interconnected and interrelated parts that 
jointly perform the organisation's purpose and that, mutually, are related to other organisations in its environment (Barile 2006, 2008; Mele et al. 2010).

From this perspective, the MBBF can be seen as a sub-system of five interrelated constructs. In order to design a model to align these constructs, the present study continues with a systems-oriented elaboration of the different interrelations between the five building blocks, studied from both their position in and contribution to the MBBF. This results in the design of the renewed evidence-based STM model and its elaboration in three renewed STM diagrams of the initial three STM-scan diagrams as introduced in Brouwer (2012).

\subsubsection{Evidence-Based Systems-Oriented Talent Management}

Looking at the MBBF (Fig. 3.1) from a systems-oriented perspective reveals three different paths between the building blocks resources and results. The first runs from resources via structure to results. The second path runs from resources via culture to results, and the third goes from resources via the higher order construct strategy towards results. The joint approach of these three paths forms the central idea behind the renewed STM. In this way, STM aligns human talent, found in resources, with the organisation's purpose, found in structure, culture and strategy, in order to achieve the predefined results.

\section{Path 1: Structure}

Organisational structure is operationalised into organisational effectiveness, defined as the efficiency with which an organisation is able to meet its objectives. It is about every employee doing what he or she does best. The main measure of organisational effectiveness for a business is generally expressed in terms of how well the achieved results compare with the predefined goals (Pedraza 2014).

Perceived from its position within the MBBF, organisational effectiveness is linked to the organisation's focus and the way the organisation is structured to achieve its goals (Yu and Wu 2009). This is related to the foundation of organisational structure (Pugh 1990). Approached from its contribution to the MBBF, Mitchell (2012) sees organisational effectiveness as a logic model that specifies how resources produce activities and output, which in turn will lead to outcomes. This is associated with the decision-making processes of organisational structure (Jacobides 2007).

In order to describe the first path of the MBBF, the interaction between the building blocks resources and structure needs to be unravelled. The interplay between resources and structure leads to a specific outcome, seen as the building block results. Since organisational effectiveness is considered as the effectuation of organisational structure, a corresponding type of resources element is required to study their interconnection. This can be found in personality facets underlying the five personality factors openness, conscientiousness, extraversion, agreeableness and neuroticism of the five factor model (FFM; Costa and McCrae 1985). More specified facets help to express the many meanings and components of personality. For example, the six 
facets of extraversion are warmth, gregariousness, assertiveness, activity, excitement seeking and positive emotions.

\section{Path 2: Culture}

Organisational culture can be approached from both an integral and an individual perspective. Whereas organisational culture defines the values and behaviours an organisation requests from its employees, organisational climate focuses on the employees' actual experiences and the attitudes or workstyles they see being rewarded and encouraged by the company (Ehrhart et al. 2014). Organisational culture represents the organisation's demonstrated image from the outside-in, found in the building block culture, and organisational climate embodies its actual present identity from the inside-out, linked to the building block resources. In studying its position in and contribution to the MBBF, organisational climate can be delineated from both a strategic approach and from a molar approach. The first approach considers organisational climate as the individual perception and representation of the work environment, focusing on a specific outcome (Kuenzi and Schminke 2009; Gimenez-Espin et al. 2013). The second approach concentrates on capturing the generic sense of the experiences people have at work (Schneider and Reichers 1983). Jointly, the strategic and molar approach convert organisational climate into a construct that represents both the position (Ravasi and Schultz 2006) and the contribution (Ehrhart et al. 2014) of the building block culture to the business purpose.

To describe the relationship of organisational climate with human talent, a second corresponding human characteristic is needed. This can be found in work values of the universal values model, or UVM (Schwartz 1992), which represents human motives and beliefs people have concerning what situations and actions are desirable in the working environment, such as independence, variety and income.

\section{Path 3: Strategy}

Business strategy, studied from an integral organisational perspective, dissects the organisation's purpose in organisational effectiveness and organisational climate. Within the MBBF, the two building blocks structure and culture jointly form their higher-order building block strategy. Whereas business strategy is seen as the execution of these two constructs, a same way of composing the building block resources is needed in order to study the interconnection between personality facets of the FFM and work values of the UVM. This was found in the concept of competences, which is the combination of these two human characteristics. Competences are defined as the sum of a person's abilities, intrinsic gifts, skills, knowledge, experience, intelligence, judgment, attitude, character and drive (Michaels et al. 2001). In the STM, this is elaborated in a set of 16 key competences, including entrepreneurship, initiative, creativity and empathy.

To link the individual competences to the integral business strategy, a higherorder construct, consisting of both a business strategy and a competence element, is required. This was found in the theory of team roles, which was first introduced by Belbin in 1981 as the result of a study on the question why some (management) teams succeed and others fail. He defined team roles as tendencies to behave, contribute and 


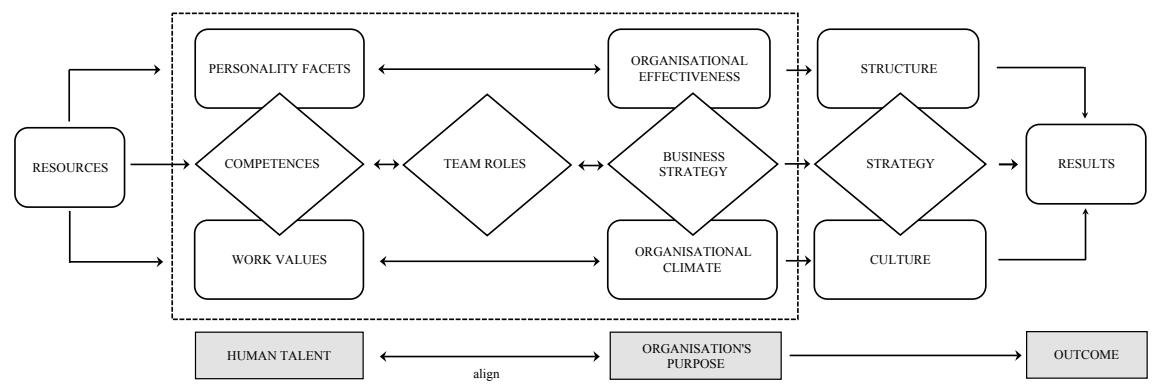

Fig. 3.2 The relationships between the STM elements and the five building blocks of the MBBF

interrelate with others in a particular way and used it to identify people's behavioural strengths and weaknesses in the workplace (Belbin 2010). In the STM, Belbin's eight team roles are defined in terms of work-related human activities, including innovate, activate and coordinate.

The different relationships between the STM elements and the building blocks are presented in Fig. 3.2. The three paths from resources to results as described above have been elaborated in the three renewed STM diagrams (Figs. 3.3, 3.4 and 3.5).

\subsection{Renewed STM Diagrams}

\subsubsection{Renewed STM Diagram 1: Aligning Organisational Structure and Human Talent}

Figure 3.3 presents the renewed version of the first STM diagram, which elaborates the systems-oriented interplay between the building blocks structure and resources of the MBBF in the relationship between organisational effectiveness and personality facets. The building block structure, seen as organisational structure, becomes tangible in the construct organisational effectiveness. Its position, dealt with as one of the management processes within the MBBF, is elaborated in the Deming quality circle (Deming 1986), known as the plan—do—check—act (PDCA) cycle, which is a frequently used problem-solving model in the field of quality management. In the cycle:

1. plan is the act of identifying opportunities and ways for improvement;

2. do refers to the actions necessary to effect the change;

3. check is the verification of whether the changes resulted in the desired improvements; and

4. act refers to what one does in response to the effects that are observed. 


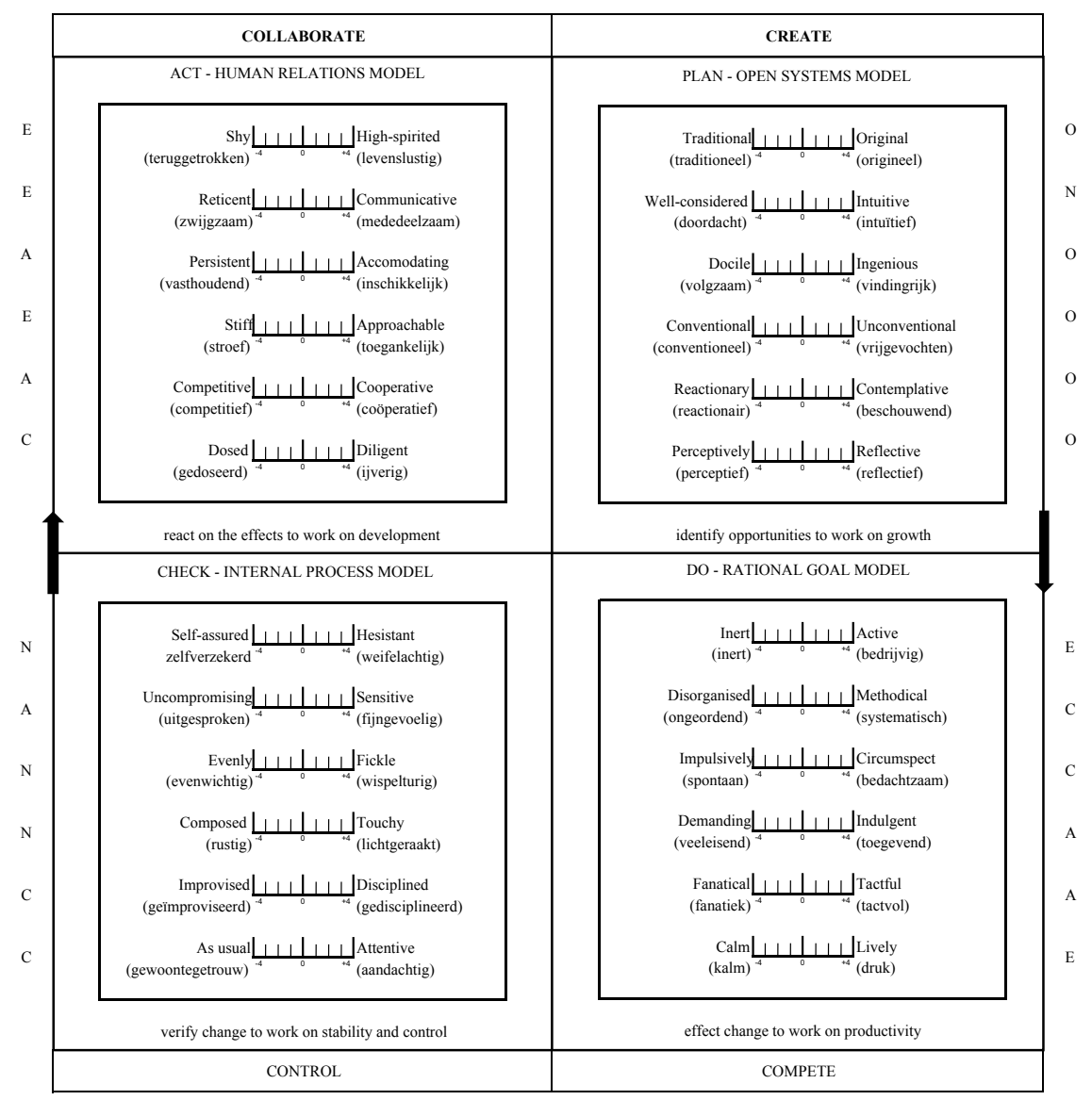

Fig. 3.3 Renewed STM diagram 1: the alignment of organisational structure and human talent, elaborated in the relationship between organisational effectiveness and personality facets

The contribution of organisational structure to the building block results becomes tangible in the competing values framework, or CVF (Quinn and Rohrbaugh 1983). The CVF is a cycle for process improvement that consists of four models:

1. the open systems model, in which growth, new resources, and external support are worked on by maintaining flexibility and availability;

2. the rational goal model, where productivity and efficiency are worked on through goal setting and planning;

3. the internal process model, in which stability and control are worked on through information management and coordination; and

4. the human relations model, in which human resources are developed by maintaining cohesion and morale (Cameron and Quinn 2011). 


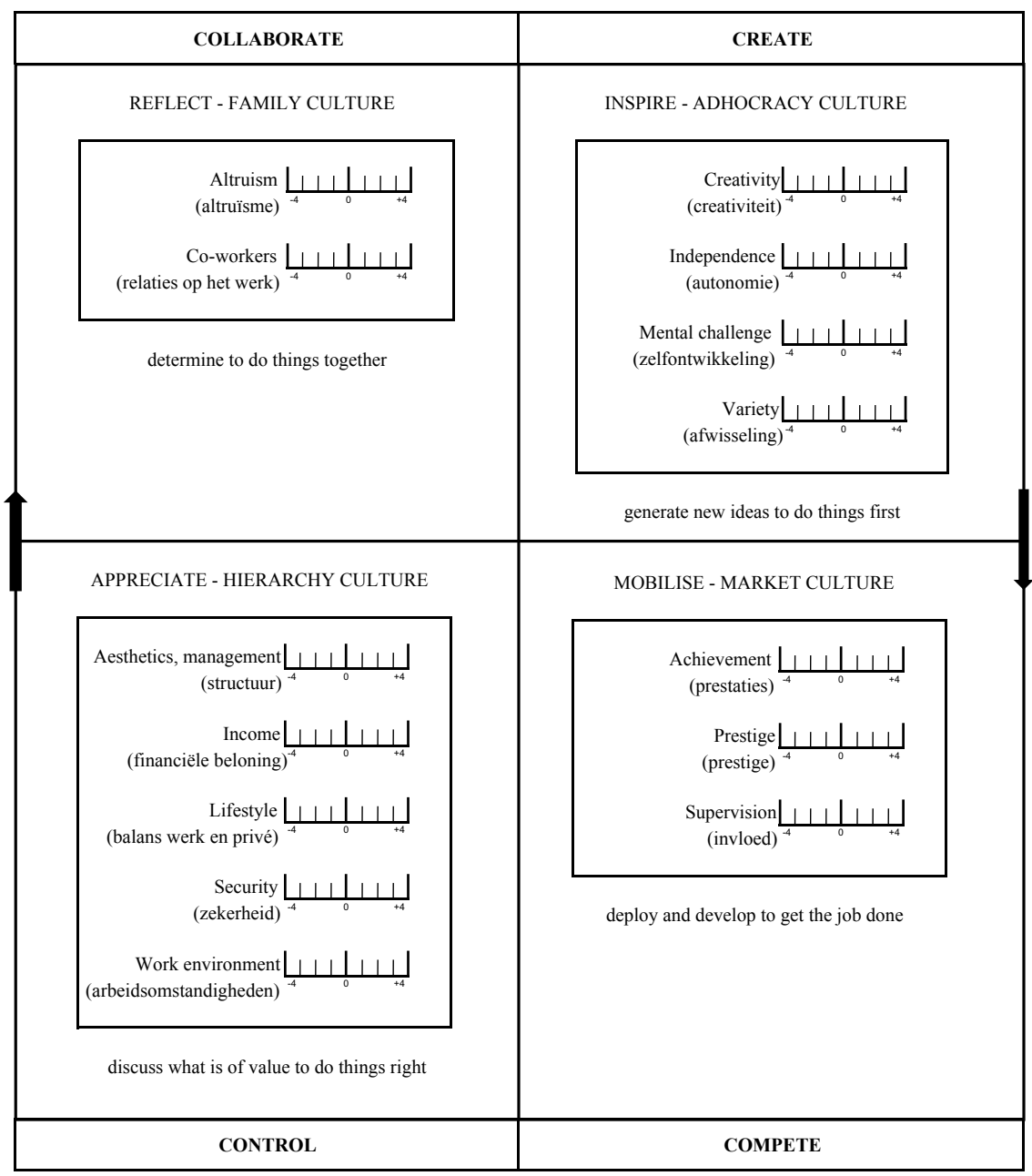

Fig. 3.4 Renewed STM diagram 2: the alignment of organisational culture and human talent, elaborated in the relationship between organisational climate and work values

The personality facets corresponding to these models emerged from the translation of each of the personality facets of the FFM (Costa and McCrae 1985) into sets of Dutch non-normative and work related synonyms and antonyms (called synsets), derived from the Dutch Idioticon of Personality (De Raad and Doddema-Winsemius 2006). This idioticon is a lexical matrix derived from the 1203 trait terms of Brokken (1978), which is used as a vocabulary to describe a person's nature.

The interconnections between the management cycle of organisational effectiveness and the lexical corresponding personality facets is grafted in the competing 


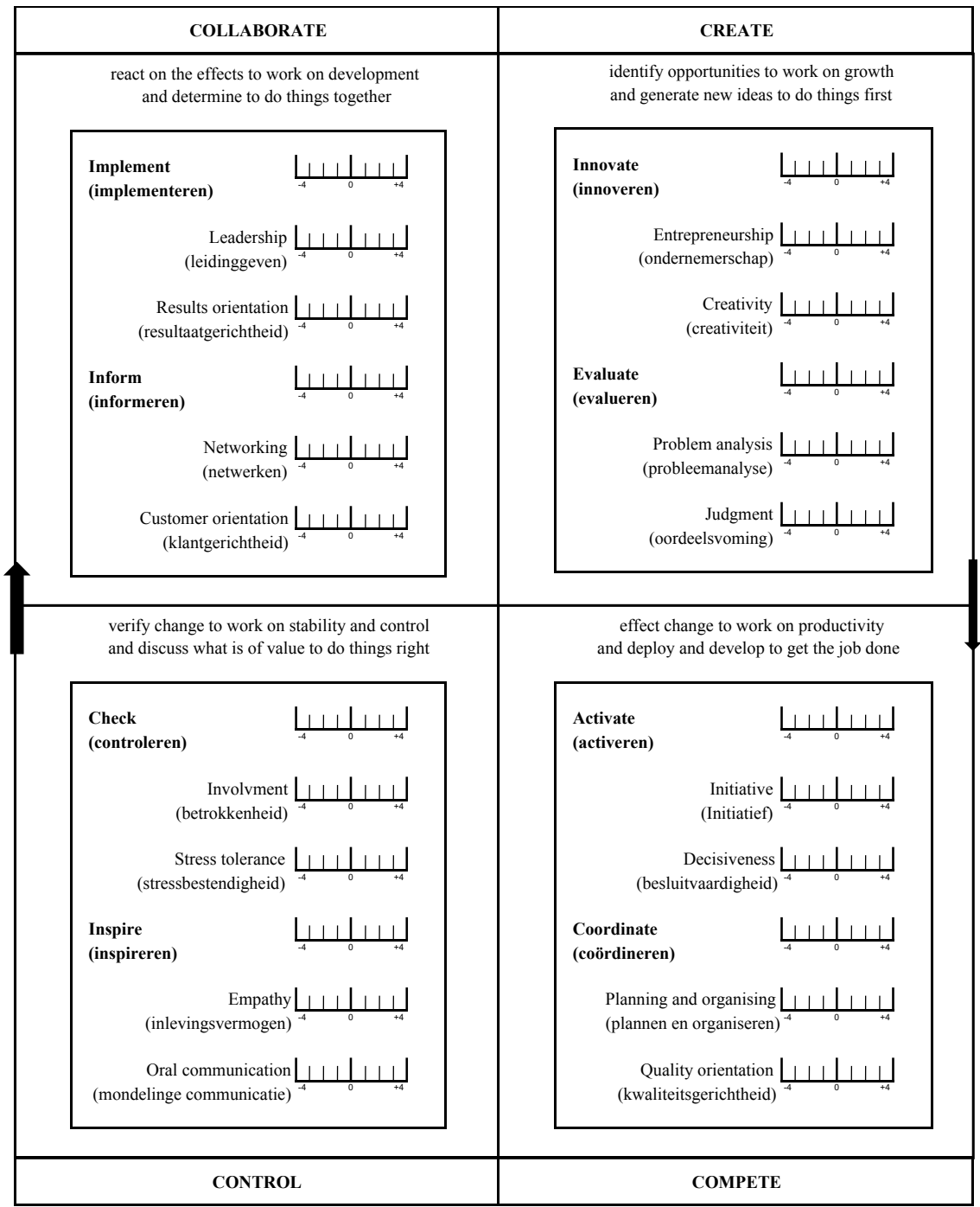

Fig. 3.5 Renewed STM diagram 3: the alignment of business strategy and human talent, elaborated in team roles as the junction in the relationship between business strategy and competences 
values leadership model, or CVLM (Cameron et al. 2014). The CVLM expresses the combination of the PDCA and the CVF in four verbs that represent human activity:

1. create, defined as 'doing new things' and considered as the junction of 'plan' and the open systems model;

2. compete, specified as 'doing things now' and perceived as the link between 'do' and the rational goal model;

3. control, determined as 'doing things right' and perceived as the junction of 'check' and the internal process model; and

4. collaborate, or 'doing things that last', considered as the link between 'act' and the human relations model.

With this, the first renewed diagram is a representation of the individual aptitude for the different phases of organisational effectiveness.

To convert this diagram into a computer based testing instrument, the sum score of each underlying five factor personality facet, measured with a five factor personality questionnaire such as the Dutch Personality test (NPT; Van Thiel 2008a), can be calculated as the sum of the raw scores on the set of corresponding items on a five-point Likert scale of that specific personality facet. The sum score then can be converted into a standardised Z-score on a bandwidth of -4 until +4 , comparable to the range of $-4 \sigma$ until $+4 \sigma$, defined as four standard deviations from the mean within a normal distributed sample. In this way it is possible to visualise the individual score between two opposite facets. For example, the raw score for the facet 'original', derived from the factor 'openness' and measured with a five factor test, is based on the responses on ten items with a raw sum score between 10 and 50. If a candidate has a raw score of 28 points, this results in a standardised Z-score of 2.23 , which implies that the individual score bandwidth on the synset traditional versus original is [ -1.77 until 2.23]. This means that the candidate has a somewhat higher aptitude for original $(2.23 / 4.00=0.56)$ than for traditional $(-1.77 /-4.00=0.44)$.

The four CVLM models each consist of six synsets of two opposite personality facets, derived from the FFM. Figure 3.3 shows that the first model 'create' consists of five synsets of the factor openness and one synset of the factor neuroticism (well considered vs. intuitive). The second model 'compete' consists of two synsets of the factor extraversion (inert vs. active and calm vs. lively) and two synsets of the factor conscientiousness (disorganised vs. methodical and impulsively vs. circumspect). The last two synsets of 'compete' were derived from the factor agreeableness. The model 'control' consists of one synset of the factor agreeableness (uncompromising vs. sensitive) and of two synsets of the factor conscientiousness (improvised vs. disciplined and as usual vs. attentive). The other three synsets were derived from the factor neuroticism. 'Collaborate', the fourth model, consists of one synset derived from conscientiousness (dosed vs. diligent) and of two synsets from agreeableness (persistent vs. accommodating and competitive vs. cooperative). The other three synsets were derived from extraversion. On average, each of the four models is built on facets of three factors of the FFM.

To find relations between various aspects of organisational effectiveness and personality facets (Brouwer 2018, Chap. 2), a lexical-semantic analysis was performed. 
Lexical analyses address a language's lexicon, or the collection of words in a language (Murphy 2003). It can be used to study word meanings, the relationships between (groups of) words and sentences, and to test semantic distances. Semantic distances are defined as the number of lexical steps required to relate the meaning and longer utterance of key terms. To calculate the semantic distances between personality facets and the four CVLM models, Open Wordnet was used, which is a lexical database that groups words together by joint meanings. The strongest relationships were found for 'collaborate', the weakest for 'compete' and 'control'. For all models, the resulting lexical-semantic distance was within four steps of Wordnet, which shows that four or less semantics were needed to link the models of organisational effectiveness to the corresponding personality facets. The ordering of personality facets in the four models was also confirmed by stepwise multiple linear regression analyses, predicting the work values from the personality facets (Brouwer and Veldkamp 2018).

\subsubsection{Renewed STM Diagram 2: Aligning Organisational Culture and Human Talent}

Figure 3.4 presents the renewed version of the second STM diagram. It visualises the elaboration of the systems-oriented interplay between the building blocks culture and resources of the MBBF in the relationship between organisational climate and work values. The building block culture becomes tangible in the construct organisational climate. Its function, seen as the motivational aspects behind the management cycle of organisational effectiveness, is elaborated in the IMAR-cycle (INK 2008). The IMAR (for inspire-mobilise-appreciate_reflect) is a method to design and control organisational climate from a 'level of excellence' perspective. The cycle is interpreted as follows:

1. inspire, which is the act of stimulating the mind and generating new ideas;

2. mobilise, or the act of deploying and developing the capabilities of all stakeholders in and around the organisation;

3. appreciate, or the act of discussing with stakeholders what is really of value; and

4. reflect, which is the act of discussing what matters, what will be possible or difficult to do, and what to do about anything that is decided on.

The impact of organisational climate on the building block results gets tangible in the four models of the organisational culture assessment instrument, or OCAI (Cameron and Quinn 2011). This quantitatively based organisational culture survey provides a framework for clarifying the underlying relationships between organisational climate and its effects on the performance of the organisation. The culture models consist of:

1. adhocracy culture, a culture that is dynamic and entrepreneurial, in which people concentrate on doing things first;

2. market culture, which is a results-oriented culture that focusses on getting the job done; 
3. hierarchy culture, where the culture is structured and controlled, with the intention of doing things right; and

4. family culture, where the culture is characterised by mentoring and nurturing, with the aim of doing things together.

The corresponding work values emerged from the UVM. The interconnections between the management cycle of organisational climate and the lexical corresponding work values are also grafted in the four models of the CVLM. With this, the second renewed diagram is an illustration of the individual affinity with the different phases of organisational climate.

To convert this diagram into a computer based testing instrument, the sum score of each work value, measured with a universal values questionnaire (the Dutch work values test; NWT; Van Thiel 2008b), can be calculated as the sum of the raw scores on the set of corresponding items on a five-point Likert scale of that specific work value. The sum score can then be converted into the standardised Z-score on a bandwidth of -4 until +4 , comparable to the range of $-4 \sigma$ until $+4 \sigma$. This makes it possible to visualise the individual score on that specific work value. For example, the work value 'independence', measured with a universal values test, is built on eight items with a raw sum score between 8 and 40 . If a candidate has a raw score of 23 points, this results in a standardised Z-score of 0.53 . This implies that the individual score bandwidth on the work value independence runs from [ -4.00 until 0.53$]$, which means that the candidate has a slightly more than average affinity with independence $(4.53 / 8.00=0.57)$.

The four CVLM models each consist of a set of work values, comparable to the clustering of work values found in earlier research (Robinson and Betz 2008; Van Thiel 2008b). A lexical-semantic analysis was performed to find relations between various aspects of organisational climate and work values (Brouwer 2018, Chap. 3). The strongest relationships were found for 'compete', the weakest for 'control'. For all models, the resulting lexical-semantic distance was between 3.2 and 4.4 steps of Wordnet. This ordering of work values in four models was also confirmed by the stepwise multiple linear regression analyses, predicting the work values from the personality facets (Brouwer and Veldkamp 2018).

\subsubsection{Renewed STM Diagram 3: Aligning Business Strategy and Human Talent}

Figure 3.5 presents the renewed version of the third STM diagram, showing the elaboration of the systems-oriented interplay between the building blocks strategy and resources of the MBBF in team roles as the junction in the relationship between business strategy and competences. The building block strategy is viewed as the joint process-oriented and human-contribution approach of both organisational effectiveness and organisational climate. The former, known as the process dimension of strategy, is elaborated in the combination of the PDCA-cycle and the IMAR-cycle. 
The latter, defined as the contribution of strategy to the building block resources, becomes visible in the combination of the four models of the CVF and the OCAI.

The corresponding competences emerged from the combination of underlying personality facets of the FFM and work values of the UVM, representing the attributeand attitude elements of the competence. The individual competences and the integral business strategy, are linked through the higher-order construct of team roles, that consists of both a business strategy and a competence element. As shown in the first two renewed STM diagrams (Figs. 3.3 and 3.4), the interconnections between the management cycle of business strategy and the lexical corresponding competences are grafted in the four models of the CVLM. With this, the third renewed STM diagram is an illustration of the individual contribution to the different phases of the business strategy.

To make the third diagram applicable as a testing instrument, the sum score of each competence can be calculated as the sum of the raw scores on the set of corresponding underlying personality facets, measured with a five factor personality questionnaire, and work values, measured with a universal values questionnaire, on a five-point Likert scale. This sum score is converted into the standardised Z-score on a bandwidth of -4 until +4 , comparable to the range of $-4 \sigma$ until $+4 \sigma$, defined as four standard deviations from the mean within a normal distributed sample. In this way, it is possible to visualise the individual score on that specific competence. The sum score on each team role is the average of the standardised sum score of the two underlying competences. For example, the competence creativity is built on the three personality facets reflective, original and ingenious and on the four work values mental challenge, creativity, independence and variety. This, for instance, results in an average standardised Z-score of 1.75, which implies that the individual score bandwidth of the candidate on the competence creativity runs from [ -4.00 until 1.75]. This means that the candidate has an aptitude of $(5.75 / 8.00=0.72)$ for creativity. If, for example, the average standardised Z-score for the competence entrepreneurship was 0.52 , then the candidate would have an aptitude of $(5.75+4.52) / 2=5.14 / 8.00$ $=0.64$ for the team role innovate.

The four CVLM models each consist of two team roles that are both built on two competences. Each competence is constructed from a set of underlying personality facets and work values. This classification of competences and team roles was confirmed by both the lexical-semantic analyses and the stepwise multiple linear regression analyses, predicting the work values with the personality facets (Brouwer 2018, Chap. 5).

First, the lexical-semantic relation between four CVLM models, 16 key competences and eight team roles was established. Then, data were collected to substantiate this relation. Factor analyses showed that the ordering of key competences could be clustered in the lexical corresponding four CVLM models. A second factor analysis of the eight team roles resulted in three clusters of team roles. It appeared that the first two models of CVLM, 'create' and 'compete', showed overlap. However, the comparable strength of the factor loadings of the team roles innovate and evaluate on the one hand and the team roles activate and coordinate on the other hand, seem 
to suggest that these are two different clusters. This implies that the team roles can also be divided into the four models.

For both the key competences and the team roles, strong reliability in terms of Cronbach's alpha $(\alpha)$ was found. The key competences show an average $\alpha$ of 0.798 within a range of [0.745-0.855]. The team roles present an average $\alpha$ of 0.811 within a range of [0.777-0.839]. According to both the Standards for Educational and Psychological testing (AERA, APA and NCME 2014) and the Dutch Committee on Tests and Testing (COTAN), a Cronbach's alpha of 0.8 or higher indicates a high reliability and is required for selection assessment tools (Evers et al. 2010). Therefore, both the composition of the key competences in underlying personality facets and work values, and the composition of the team roles out of the combination of two key competences, can be measured in a reliable way. A nuance should be made for the team roles, since the increase in the number of combined personality facets and work values behind the team role in itself contributes positively to the reliability coefficient.

\subsection{Implications of the STM for Educational Measurement}

STM is developed as an instrument to align human talent and business purpose. Psychological tests are used to measure human talent, and five managerial building blocks (Nieuwenhuis 2006) are applied to develop three renewed STM diagrams that connect human resources and results through interconnecting managerial building blocks. The logic that underlies the STM can be generalised to other applications. It could, for example, be applied in the educational world.

The purpose of education could be formulated as to have learners graduate with the skills needed to succeed. The results could be expressed in how well these skills are mastered. Dependent on the kind of education; primary, secondary or tertiary, different skills need to be obtained. Primary education prepares children for secondary education, secondary education prepares them for college, and college prepares students for the labour market. To operationalise these skills, learning goals have been formulated and curricula have been developed and implemented. For the Dutch educational system, for example, the learning goals that have to be mastered by the end of primary education are well documented for the various domains (Rijksoverheid 2006). The goals for the various levels of secondary education are specified in syllabi at course level (www.examenblad.nl). All of these learning goals are content oriented. With respect to language, for example, pupils are expected to be able to gain information from spoken language and to represent the information in a structured way, either orally or written, by the end of primary education. Recently, a discussion was started to extend this set of goals by incorporating 21 st century skills.

Human talent in education is often expressed in terms of how well children perform with respect to educational tests. These tests could be developed by a teacher, teacher teams, publishers who developed the learning materials, or by specialized test publishers. The content of the tests is derived from the general learning goals. 
Since these goals have to be formulated for the end of primary, secondary or tertiary education, they are very general. Therefore, they have been operationalised in learning lines, that specify when children or students have to be able to master sub-goals. These sub-goals can be translated into test goals. Finally, for these test goals, items can be developed that are administered to children or students in educational tests. The learning lines are generally content oriented, which is also reflected in the items. For this process, see also the 12-steps test development framework of Downing and Haladyna (2009).

One of the first things that can be noted when the STM approach is applied to the educational system, is that human talent is much broader defined than content related ability, which is the topic of most educational assessments. STM studies human talent by including personality factors, work values, and competences. These personality factors can be much broader than cognitive abilities. Besides, competences and work values could also contribute to educational outcomes.

In the STM model, personality factors are operationalized by the FFM. The first STM diagram models the relation between the facets of the FFM and organisational effectiveness. The third diagram models the relation between the facets and business strategy via competences and team roles. Even though the concepts of organisational effectiveness and business strategy might be hard to translate to the world of educational sciences, the more general building blocks of structure and strategy play an important role in education as well. Structure could be related to what pupils and students learn, strategy can be related to how they learn.

The relation between the FFM and academic performance is studied extensively (Poropat 2009). Academic performance was found to correlate significantly with agreeableness $(r=0.07)$, conscientiousness $(r=0.19)$, and openness $(r=0.10)$. Conscientiousness correlated the highest, almost as high as intelligence $(r=0.23-$ $r=0.56)$. Even though a significant relation between personality and performance has been reported, personality factors are almost never taken into account in assessment in the educational system. Two reasons can be given. The first one is a statistical reason: the correlations are relatively small, even conscientiousness only explains four percent of the variance. Secondly, educational assessments primarily focus on whether cognitive goals have been reached. However, this might change in the near future. As found in the study of Komarraju et al. (2009) on the connection between personality and how students learn (strategy), the relation between personality and what students learn (structure) could become more important when education focuses on competences and 21 st century skills as well, rather than content related learning goals only.

Within the STM, competences are related to business strategy via team roles. The concept of competences has been applied in the educational context as well. Mulder et al. (2007) provide an overview of various traditions that used the concept of competences. They distinguished between a behaviourist, general and cognitive approach, where the STM model seems to fit within the behaviouristic approach. Even though there has been a considerable tradition of using competences in education, especially in vocational education, there are still many educational programmes in which the learning goals have not been formulated in terms of competences. STM 
demonstrates how competences can be used to align talent and purpose. It therefore supports a wider use of competences in formulating purpose of learning as well.

The third personality characteristic that is distinguished in the STM is work values. The STM showed how work values are related to culture and contribute to results. Adding the building block culture to a model that relates human talent to educational outcomes is not very common in educational measurement. The most general factors that are taken into consideration are student characteristics, teacher characteristics, school characteristics and teaching characteristics. Culture is related to why and when students learn. Therefore, work values could be studied as student characteristics influencing learning results as well. However, in most studies, parental education, parental occupational status, income, and social economic status are taken into consideration instead. In order to develop 21 st century skills, the what, the why and the when are drivers behind the how. Knowing when a student will be intrinsically motivated to learn (why) and knowing when a student will be most effective in his/her learning process (what), provides both teachers and school systems with insights how to optimise the learning results in terms of both cognitive and social-emotional skills that are needed to thrive in the modern work-environment.

Overall, when the STM is translated to the educational context, quite a few interesting observations can be made. The STM provides a more general framework for aligning talent and outcomes. Educational measurement could therefore be enriched by adopting this broader approach. Two applications might especially profit from such an approach. In the Netherlands, the transition from primary to secondary education is quite a hurdle for many children. Secondary education in the Netherlands distinguishes various levels and the problem is to assign each child to his/her appropriate level. Based on performance in primary education, the teacher in the final grade advises which level would suit a child best. After this advice, children participate in one of five national tests at the end of primary education, as a kind of objective second opinion. The results of these national tests can be used to adjust the advice to a higher level. The national tests mainly focus on performance in language and math. The STM showed that adding other personality factors, work values and competences might result in a more appropriate advice.

A second application is in the design of teaching. The STM shows that optimal alignment of talent and purposes leads to the best outcomes. The assessment of human talent is an important ingredient in this process. When translated to the educational context, this implies that educational measurement is a considerable ingredient in the alignment of talent and educational results. There is quite some debate about the role of educational measurement in the teaching process. Teachers often complain that too much time is spent on testing rather than teaching. Besides the learning goals that have been defined for primary and secondary education, schools tend to focus on the more general development of children as good citizens. Teaching to the test does have a very negative connotation in this debate (Onderwijsraad 2013). From the STM it can be learned, however, that efficient use of educational measurement in the educational process will lead to better outcomes. Aligning learning goals and educational measurement, as was proposed by Scheerens (2016), could further increase the outcomes of the educational processes. 


\subsection{Conclusion, Limitations, and Recommendations}

\subsubsection{Conclusion}

This chapter introduced the design of the renewed evidence-based STM model and its elaboration in three renewed STM diagrams, that could take the place of the initial three diagrams as introduced in Brouwer (2012). The management building blocks framework (MBBF; Nieuwenhuis 2006) and the systems theory (Katz and Kahn 1966; Meadows 2008) were used to elaborate the interrelations within the new STM model. This provided in a renewed way of linking human talent to the core elements of the organisation's purpose (Barile 2006, 2008; Mele et al. 2010), and is assumed to create a fit at the level of a joint corporate and personal identity instead of at the level of a specific job profile that in our ever-changing world is subject to continuous alteration.

The first renewed STM diagram (Fig. 3.3) is seen as an improved and evidencebased rendition of the initial 2012 version of the first Dutch STM-scan diagram. In both versions, the 24 personality facets are lexically derived from the 24 FFM labels including their lexical antonym. Whereas in the initial diagram, the antonyms were directly derived from the Van Dale Thesaurus, a lexicon consisting of synonyms and antonyms, the antonyms in the renewed version were derived from the list of characteristics describing both poles of each of the five factor personality facets, as documented in the Dutch 'Idioticon of Personality' (De Raad and DoddemaWinsemius 2006). In the initial 2012 version, the 24 personality facets and their antonyms were clustered in the four steps of the primary business process that stem from the business purpose (idea-plan-form-action). In the renewed version of the first diagram, business purpose is further detailed in the content- and contribution side of organisational effectiveness, and is considered the effectuation of the building block structure found in the MBBF. The lexical-semantic linking of this block to the personality facets through the optimal path similarity results in the first path that runs from resources through structure to results.

The second renewed STM diagram (Fig. 3.4) is introduced as an improved and evidence-based version of the initial second 2012 STM-scan diagram. In both editions, the work values are lexically derived from the UVM and clustered in four higher-order culture types. In the initial version, this resulted in four culture types with four corresponding fundamental attitudes, representing an individual's social orientation. Within the renewed version, the work values were clustered in higherorder culture types, similar to the ordering of work values of Schwartz (1992), Ros et al. (1999), Robinson and Betz (2008), Daehlen (2008), and Van Thiel (2008b). Business purpose is further detailed in the content- and contribution side of organisational climate and is considered the effectuation of the building block culture found in the MBBF. The lexical-semantic linking of this block with the work values through the optimal path similarity leads to the second path that runs from resources through culture to results. 
The third renewed STM diagram (Fig. 3.5) is presented as an improved and evidence-based version of the initial third STM-scan diagram. In the initial 2012 version, the 24 personality facets and their antonyms of the first STM diagram were used to calculate the amount of disposition for a series of 24 competences. Each competence was built on a combination of three of the 24 personality facets measured in the first STM diagram. The 24 competences were clustered in eight team roles, each consisting of three competences representing the four steps of the primary business process that stem from the business purpose. Within the renewed third STM diagram, combinations of both personality facets (first diagram) and work values (second diagram) are used to calculate the amount of disposition for a series of 16 key competences. The algorithms of combinations of personality facets and work values per key competence are confirmed by both the lexical-semantic classification, found in Brouwer (2018, Chaps. 2 and 3), and the linear regression models found in Brouwer and Veldkamp (2018). Each of the 16 key competences is related to a series of lexical-semantic synonyms found in existing competence frameworks in which the different competences are clustered in: (1) strategic competences, (2) tactical competences, (3) communicating competences, and (4) operational competences. The 16 key competences are clustered in eight team roles, each consisting of two key competences.

In the new version of the third diagram, business purpose is further detailed in the process-oriented and human-contribution approach of business strategy. The process-oriented approach is dealt with as the content side of both organisational effectiveness and organisational climate. The human-contribution approach is seen as the contribution side of both organisational effectiveness and organisational climate. This operationalisation of the construct business strategy is considered the effectuation of the building block strategy found in the MBBF. The renewed versions of the STM diagrams contribute in more detail to the alignment of the organisation and its employee.

All in all, the design and validation of the renewed STM contributes to a sharp and objective picture of the match between people and the organisation, by linking human characteristics to managerial building blocks. The three renewed STM diagrams jointly make up a potential new version of the systems-oriented assessment instrument STM-scan, both in Dutch and in English. In completing a five factor personality test, such as the NPT and an universal values inventory, like the NWT, the individual contribution to the four models of organisational effectiveness, organisational climate and business strategy can be measured and reported in the three renewed STM diagrams that jointly represent three alignment paths between resources, the organisation and its intended results.

\subsubsection{Application to Educational Measurement}

In order to modernise education, it is required to measure the what, why, when and how of the learning process. It is not only important to know what a student should 
learn in order to participate in the working environment, but also when and under which circumstances he or she is motivated to learn. This will provide earlier and better insight in how every individual reaches maximal learning results in his or her own way. This specifically concerns the results that consist of both cognitive and social-emotional skills, which will prepare students for the sustainable employability our rapidly changing world asks for. Therefore, it is necessary to develop skills that help to use acquired knowledge in different ways and situations. This will contribute to the prevention of school- and work dropout and the entailed costs.

\subsubsection{Limitations}

Before turning to the recommendations and implications of this study, there are some limitations to take into account. The renewed evidence-based systems-oriented talent management model is built on three different paths between the building blocks resources and results, found in the MBBF. Therefore, the intermediate building blocks structure, culture and strategy are theoretically linked to organisational effectiveness, organisational climate and business strategy. The building block resources is detailed in personality facets, work values, competences and team roles. The different relationships, found in the three paths between resources and results are partly established on the basis of interpreting different text corpuses. This could imply that other existing lexical-semantic relations, that might argue against the present used relations, may have been overlooked. However, since the majority of the lexicalsemantic relationships are empirically substantiated by stepwise multiple regression analyses, confirmatory factor analyses and multitrait multimethod matrixes, this supports the internal consistency reliability and construct validity of the renewed STM diagrams.

A second limitation of this study is that the renewed STM diagrams so far have not yet been operationalised in a new version of the web-based STM-scan assessment instrument. Therefore, the utility of the renewed model could not yet be evaluated based on practical experience.

A third limitation concerns the definition of competences. The educational literature shows that different competency models were developed in different traditions (Mulder et al. 2007). This is also the case for organisational practice, where large companies often create their own competency-language. In the development of STM, the overlap between a series of those different models was studied. This resulted in a set of 16 key competences, with underlying synonyms. This makes the STM an instrument with which customer-specific competency-languages can be converted to the 16 key competences. In this way it is possible to measure different competence models in the same way. However, in practice this turns out to be a difficult task, that asks for a thorough understanding and knowledge of the definitions for and distinctions between the different competences. 


\subsubsection{Recommendations and Implications}

Effective test development requires a systematic, well-organised approach to ensure sufficient validity evidence to support the proposed inferences from the test scores. Therefore, it is recommended to use the 12-steps test development framework of Downing and Haladyna (2009), in order to implement the renewed STM diagrams in practice. Part of this development process should be the training of STM experts and the implementation of a periodic evaluation cycle of the psychometric quality and utility of the renewed assessment instrument.

Another recommendation concerns the starting point of the measurement. In its current composition, the renewed STM model is filled with the test results of an individual's scores on a set of human characteristics, which builds the relationship with the management building blocks of the MBBF. In addition, the field of management science has introduced different inventories for measuring a combination of these management building blocks (Cameron and Quinn 2011; Cameron et al. 2014). An interesting follow-up study would be to investigate whether the STM model can also be measured the other way around by predicting human characteristics with the help of a managerial inventory. The present study lays the foundation for this follow-up research.

In conclusion, the renewed evidence-based STM model and diagrams introduced in this chapter, contribute to the future bridging of the gap between psychological questionnaires for testing human characteristics and models for unravelling managerial building blocks. In doing so, insight is provided in how adaptive enterprises ought to be organised these days and how to give shape to the corresponding upscaling that is required of their talent management experts. Subsequently, the study joined the debate on how the educational field ought to implement a wider approach on learning outcomes, by studying the structure (what), culture (why and when) and the strategy (how) sides of educating and measuring 21 st century skills next to cognitive skills.

\section{References}

American Educational Research Association AERA, American Psychological Association APA, National Council on Measurement in Education NCME. (2014). Standards for educational and psychological testing. Washington, DC: AERA.

Barile, S. (2006). The company as a system. Contributions on the viable system approach, part I. Torino: Giappichelli.

Barile, S. (2008). The company as a system. Contributions on the viable system approach, part II. Torino: Giappichelli.

Belbin, M. R. (2010). Management teams: Why they succeed or fail, 3rd revised ed. London: Taylor $\&$ Francis Ltd.

Berger, A., \& Berger, D. R. (2011). The talent management handbook (2nd ed.). New York: McGrawHill.

Brokken, F. B. (1978). The language of personality, unpublished thesis. University of Groningen.

Brouwer, A. J. (2012). STM-scan, handboek voor het systeemgericht managen van talent. Vaassen, Nederland: A.J. Brouwer. 
Brouwer, A. J. (2018). Systems-oriented talent management. A design and validation study (Doctoral dissertation). Retrieved from https://doi.org/10.3990/1.9789036546843.

Brouwer, A. J. \& Veldkamp, B. P. (2018). How age affects the relation between personality facets and work values of business and private bankers. Journal of Work and Organizational Psychology. Advance online publication https://doi.org/10.5093/jwop2018a20.

Cable, M., \& Yu, K. Y. T. (2007). How selection and recruitment practices develop the beliefs used to assess fit. In C. Ostroff \& T. A. Judge (Eds.), Perspectives on organizational fit (pp. 155-182). New York: Taylor \& Francis-Group LLC.

Cameron, K. S., \& Quinn, R. E. (2011). Diagnosing and changing organizational culture: Based on the competing values framework (3rd ed.). San Francisco: Jossey-Bass.

Cameron, K., Quinn, R. E., \& Degraff, J. (2014). Competing values leadership (2nd ed.). Camberley, Surrey, UK: Edward Elgar.

Capra, F. (1997). The web of life. New York: Doubleday-Anchor Book.

Costa, P. T., Jr., \& McCrae, R. R. (1985). The NEO personality inventory manual. Odessa, FL: Psychological Assessment Resources.

Daehlen, M. (2008). Job satisfaction and job values among beginning nurses: A questionnaire survey. International Journal of Nursing Studies, 45, 1789-1799.

De Raad, B., \& Doddema-Winsemius, M. (2006). De Big 5 persoonlijkheidsfactoren: Een methode voor het beschrijven van persoonlijkheidseigenschappen. Amsterdam: Uitgeverij Nieuwezijds.

Deming, W. E. (1986). Out of the crisis. Cambridge, MA: Massachusetts Institute of Technology, Center for Advanced Engineering Study.

Downing, S. M., \& Haladyna, T. M. (2009). Twelve steps for effective test development. In S. M. Downing \& T. M. Haladyna (Eds.), Handbook of test development (pp. 3-25). New York: Routledge.

Ehrhart, M. G., Schneider, B., \& Macey, W. H. (2014). Organizational climate and culture: An introduction to theory, research, and practice. London: Taylor \& Francis.

Evers, A., Lucassen, W., Meijer, R., \& Sijtsma, K. (2010). COTAN Beoordelingssysteem voor de kwaliteit van tests. Amsterdam: NIP/COTAN.

Galbraith, J. R. (2002). Designing organizations: An executive guide to strategy, structure and process. New York: Wiley.

Gimenez-Espin, J. A., Jiménez-Jiménez, D., \& Martínez-Costa, M. (2013). Organizational culture for total quality management. Total Quality Management \& Business Excellence, 24(5-6), 678-692.

Hendricks, K., \& Singhal, V. (1996). Quality awards and the market value of the firm: An empirical investigation. Management Science, 42(3), 415-436.

Instituut Nederlandse Kwaliteit (INK). (2008). Introductie, inhoud en toepassing van het INK managementmodel. Zaltbommel, Nederland: INK projectgroep 'vernieuwing INK'.

Jacobides, M. G. (2007). The inherent limits of organizational structure and the unfulfilled role of hierarchy: Lessons from a near-war. Organizational Science, 18(3), 455-477.

Katz, D., \& Kahn, R. L. (1966). The social psychology of organizations. New York: Wiley.

Komarraju, M., Karau, S. J., \& Schmeck, R. R. (2009). Role of the Big Five personality traits in predicting college students' academic motivation and achievement. Learning and Individual Differences, 19(1), 47-52.

Kuenzi, M., \& Schminke, M. (2009). Assembling fragments into a lens: A review, critique, and proposed research agenda for the organizational work climate literature. Journal of Management, 35(3), 634-717.

McDonnell, A., \& Collings, D. G. (2011). The identification and evaluation of talent in MNE's. In H. Scullion \& D. G. Collings (Eds.), Global talent management. New York: Routledge.

Meadows, D. H. (2008). Thinking in systems: A primer. London: Chelsea Green Publishing.

Mele, C., Pels, J., \& Polese, F. (2010). A brief review of systems theory and their managerial applications. Service Science, 2(1), 126-135.

Michaels, E., Handfield-Jones, H., \& Axelrood, B. (2001). The war for talent. Boston: Harvard Business School. 
Mitchell, G. E. (2012). The construct of organizational effectiveness: Perspectives from leaders of international nonprofits in the United States. Nonprofit and Voluntary Sector Quarterly, 42(2), 324-345.

Mulder, M., Weigel, T., \& Collins, K. (2007). The concept of competence in the development of vocational education and training in selected EU member states: A critical analysis. Journal of Vocational Education \& Training, 59(1), 67-88.

Murphy, M. L. (2003). Semantic relations and the lexicon: Antonymy, synonymy and other paradigms. Cambridge, UK: Cambridge University Press.

Nag, R., Hambrick, D. C., \& Chen, M. J. (2007). What is strategic management, really? Inductive derivation of a consensus definition of the field. Strategic Management Journal, 28(9), 935-955.

Nieuwenhuis, M. A. (2006). The art of management. Retrieved on January 15, 2014 from http:// www.the-art.nl.

Onderwijsraad. (2013). Een smalle kijk op onderwijskwaliteit [In Dutch], Onderwijsraad.

Pedraza, J. M. (2014). What is organisational effectiveness and how an organization could achieve it. Retrieved December 1, 2017, from https://www.researchgate.net/post/What_is_organisational_ effectiveness_How_an_organisation_could_achieve_it.

Peters, T. J., \& Waterman, R. H. (1998). In search of excellence, lessons from America's best run companies. New York: Warner Books.

Poropat, A. E. (2009). A meta-analysis of the five-factor model of personality and academic performance. Psychological Bulletin, 135(2), 322.

Pugh, D. S. (1990). Organization theory: Selected readings. Harmondsworth: Penguin.

Quinn, R.E., \& Rohrbaugh, J. (1983). A spatial model of effectiveness criteria: Towards a competing values approach to organisational analysis. Management Sciences, 29(3), 363-377.

Ravasi, D., \& Schultz, M. (2006). Responding to organizational identity threats: Exploring the role of organizational culture. Academy of Management Journal, 49(3), 433-458.

Rijksoverheid. (2006). Kerndoelenboekje [learning goals primary education]. Retrieved from: www. rijksoverheid.nl/documenten/rapporten/2006/04/28/kerndoelenboekje.

Robinson, C. H., \& Betz, N. E. (2008). A psychometric evaluation of super's work values inventoryrevised. Journal of Career Assessment, 16(4), 456-473.

Ros, M., Schwartz, S. H., \& Surkiss, S. (1999). Basic individual values, work values, and the meaning of work. Applied Psychology: An International Review, 48(1), 49-71.

Scheerens, J. (Ed.). (2016). Opportunity to learn, curriculum alignment and test preparation: A research review. Berlin: Springer.

Schmidt, F. L., \& Hunter, J. E. (1998). The validity and utility of selection methods in personnel psychology: Practical and theoretical implications of 85 years of research findings. Psychological Bulletin, 124, 262-274.

Schmidt, F. L., Oh, I. S., \& Shaffer, J. A. (2016). The validity and utility of selection methods in personnel psychology: Practical and theoretical implications of 100 years of research findings. Working paper ResearchGate, 1-73.

Schneider, B., \& Reichers, A. E. (1983). On the etiology of climates. Personnel Psychology, 36, 19-39.

Schoonman, W. (2013). Mensen beoordelen, voor HR professionals. Amsterdam: De Witte Ridders.

Schwartz, S. H. (1992). Universals in the content and structure of values: Theoretical advances and empirical tests in 20 countries. Advances in Experimental Social Psychology, 25, 1-65.

Smith, M., \& Robertson, I.T. (1986). The theory and practice of systematic staff selection. London: Macmillan Press

Tillema, K., \& Markerink, F. (2006). Gericht presteren met het INK-managementmodel, van visie naar actie. Deventer: Kluwer.

Van Beirendonck, L. (2010). Iedereen content, nieuwe paradigma's voor competentie- en talentmanagement. Schiedam, Nederland: Uitgeverij Lamnoo.

Van Thiel, E. (2008a). Handleiding Nederlandse Persoonlijkheidstest, Nijmegen Nederland: 123test B.V. 
Van Thiel, E. (2008b). Handleiding Nederlandse Werkwaardentest, Nijmegen, Nederland: 123test B.V.

Wit, B., \& Meyer, R. (2011). Strategy Synthesis, resolving strategy paradoxes to create competitive advantage. Hamsphire: Cengage Learning EMEA.

$\mathrm{Yu}, \mathrm{T}$., \& Wu, N. (2009). A review study on the competing values framework. International Journal of Business and Management, 4, 37-42.

Open Access This chapter is licensed under the terms of the Creative Commons Attribution 4.0 International License (http://creativecommons.org/licenses/by/4.0/), which permits use, sharing, adaptation, distribution and reproduction in any medium or format, as long as you give appropriate credit to the original author(s) and the source, provide a link to the Creative Commons license and indicate if changes were made.

The images or other third party material in this chapter are included in the chapter's Creative Commons license, unless indicated otherwise in a credit line to the material. If material is not included in the chapter's Creative Commons license and your intended use is not permitted by statutory regulation or exceeds the permitted use, you will need to obtain permission directly from the copyright holder.

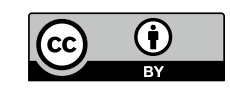

